\title{
Linking Constructivism Theory to Classroom Practice
}

\author{
Mercy M. Mugambi* \\ University of Nairobi, Kenya
}

*Corresponding Author: Mercy M. Mugambi, University of Nairobi, Kenya

\begin{abstract}
One of the most influential factors on learner success is the classroom teaching methodology that the teacher adopts. This paper focuses on constructivism theory in relation to classroom practice. The theory is associated with the Swiss psychologist Jean Piaget (1896-1980) and Mark Baldwin (1861-1934).Sources of constructivism which include; cybernetics control theory and analysis of communication and language stimulated by computer science have also been discussed. Among the prominent people in support of constructivism are Vygotsky who introduced the social aspect of learning of constructivism and defined the zone of proximal learning according to which learners solve problems beyond their actual development level through collaboration. Bruner gave emphasis to active learning and viewed learning as a social process where learners construct new concepts based on current. Paradigms of constructivism for curriculum design, the Cognitive and social constructivism have been expounded to explain development of new knowledge. Appropriate strategies and activities for using constructivism in the classroom have been presented and a comparison between traditional and a constructivist class made. Assessment in constructivism teaching must adopt appropriate methods which include oral discussion, mind mapping, hand-on activities and pre-testing as opposed to traditional tests. The paper concludes that Constructivism has the major purpose of enabling learners construct new knowledge through multiple representation, active engagement, collaboration and inquiry with the teacher acting as a facilitator.
\end{abstract}

Keywords: Constructivist Theory, Construction, Cognitive Constructivism, Social Constructivism, Collaborative Learning, Learning Environment, Classroom Practice.

\section{INTRODUCTION}

Constructivism is a theory of knowledge with roots in philosophy, psychology and cybernetics. It is based on observation and scientific study about how people learn. It states that people construct their own understanding and knowledge of the world through experiencing things and reflecting on those experiences. In knowledge development when we experience something new, we have to conceive it with our previous ideas and experience, may be changing what we believe, or may be discarding the new information as irrelevant. In any case we are creators of our own knowledge. To do this, we must ask questions, explore and assess what we know. Accordingly, constructivism asserts that: Knowledge is not passively received but actively built up by the cognizing subject and that the function of cognition is adaptive and serves the organization of the experiential world. Constructivists believe that learners construct their own meaning through active engagement and by constructing their own representation of what they know. Students learn from thinking and doing, and thinking results from an activity (Jonassen, Peck, \& Wilson, 1999). In the constructivist classroom, students interact with the environment and create their own interpretation of the world instead of being mere recipients of information transmitted by the teacher(Jonassen, 2000). The teacher motivates learners by proposing a topic or presenting a case with emphasis on the big concept. The purpose is to trigger learners' curiosity to investigate and learn more on the topic.

\section{SOURCES AND HiSTORY OF CONSTRUCTIVISM}

The first explicit formulation of constructivist theory of knowledge was proposed by Giambattista. He coined the Latin phrase "verum estipsum factum" and explained that to know something means to know what parts it is made of and how they have been put together. In the modern psychology, the motion of cognitive construction was first forced into a major component theory by James Mark Baldwin (1861-1934) and jean Piaget (1896-1980) .Cybernetic and control theory being concerned with self-regulating systems, developed a similar approach to cognition according to which adaptation to the environment and a viable conception of the world must and can be constructed from input of 
"information" (Von Foerster (2002). Another source of constructivism was the analysis of communication and language stimulated by computer science. Language users build up their meanings on bases of their individual experience and the meanings remain subjective, no matter how much they become modified and homogenized through the subjects' interaction with other language users. From the constructivist point of view, meanings are conceptual structures and as such, to a large extent influence the individual construction and organization of his/her experiential reality.

The concept of constructivism has roots in classical antiquity, going back to Socrates dialogue with his followers, in which he asked directed question that led his students to realize for themselves weaknesses in their thinking. The Socrates dialogue is still an important tool in the way constructivist educators assess their student's learning and plan new learning experiences. Jean Piaget and John Dewey developed theories of childhood development and education, what we now call progressive education that led to the evolution of constructivism. Piaget believed that humans learn through the construction of one logical structure after another. He also concluded that the logic of children and their modes of thinking are initially entirely different from those of adults. Dewey called for education to be grounded on real experience. He wrote, "if you have doubts about how learning happens, engage in sustained inquiry: study, ponder, consider alternative possibilities and arrive at your belief grounded in evidence". Inquiry is a key part of constructivist learning. Among the educators, philosophers, psychologists and sociologists, who have added new perspectives to constructivist learning theory and practices, are;

Vygotsky- who introduced the social aspect of learning into constructivism. He defined the "zone of proximal learning" according to which students solve problems beyond their actual developmental level (but within their level of potential development) under adult guidance or in collaboration with more capable peers.

Vygotsky's theory presents three principles

- Making meaning- the community places a central role and the people around the student greatly affect the way he/she sees the world.

- Tools for cognitive development- the type and quality of these tools (culture, language) determine the Pattern and rate of development

- The zone of proximal development- problem solving skills of tasks can be placed into categories.

Bruner (1996) initiated curriculum change based on the notion that learning is an active, social process in which students constructs new ideas or concepts based on their current knowledge. According to him, learning is a social process whereby students construct new concepts based on current. The student selects information, constructs hypothesis and makes decisions, with the aim of integrating new experiences into his existing mental constructs. It is cognitive structure that provides meaning and organization to experiences and allows learners to transcend the boundaries of the information given. For him, learner independence fostered through encouraging students to discover new principles of their own accord, lies at the heart of effective education. Moreover, curriculum should be organized in a spiral manner so that students can build upon what they have already learnt. In short, principles that permeate Bruner' theory are the following;

- Instruction must be commensurate with the experiences that make the students willing and able to learn (Readiness).

- Instruction must be structured so that it can be easily understood by the students (spiral organization)

- Instruction should be designed to facilitate extrapolation (going beyond the information given).

Bruner viewed learning as an active social process in which students construct new ideas or concepts based on current knowledge. As far as instruction is concerned, the instructor should try and encourage students to discover principles by themselves. The instructor and student should engage in an active dialogue. Bruner holds that a theory of instruction should address four major aspects:

- Predisposition toward learning. 
- The ways in which a body of knowledge can be structured so that it can be easily grasped by the learner.

- The most effective sequence in which to preset material.

- The nature and pacing of rewards and punishments.

His view is that good methods of structuring knowledge should result in simplifying, generating new propositions, and increasing the manipulation of information. He believed that instruction must be concerned with the experiences and contexts that make the learner willing and able to learn. By providing opportunities for independent thinking, constructivism allows students to take responsibility of their own learning by framing questions and then analyzing them.

\section{PARAdigms OF CONSTRUCTIVISM FOR CURRICUlum DESIGN}

\subsection{Cognitive Constructivism}

Cognitive or Piagetian constructivists regard the purpose of education as educating the individual child in a way that supports the child's interests and needs. This approach assumes that students come to classroom with ideas, beliefs and opinions that need to be altered or modified by teachers who facilitate this alteration by devising tasks and questions that create dilemmas, for students. Knowledge construction occurs as a result of working through these dilemmas. Characteristic instructional practice include "discovery learning" and hands on activities such as using manipulative; student tasks that challenge existing concepts and thinking processes; questioning techniques that probe students beliefs and encourage examination and testing of these beliefs. The internal development of learners is the focus of the teaching environment, the social and historical context. Issues of power, authority and place of formal knowledge in the learning environment are not emphasized. It is essentially a decontextualized approach to learning and teaching.

\subsection{Social Constructivism}

Social or Vygotskian constructivism emphasize education for social transformation and reflects a theory of human development that situates the individual within a social cultural context. Individual development derives from social interactions within which cultural meanings are shared by the group and eventually internalized by the individual. Through interactions, individuals construct of both the individual and the environments are changed. The subject of study is the dialectical relationship between the individual and the social and cultural milieu. The approach assumes that theory and practice do not develop in vacuum; they are shaped by dominant cultural assumptions. Formal knowledge, the subject of instruction and the manner of presentation are influenced by the historical and cultural environment that generated them.

\subsection{Principles of Constructivism}

The following are guiding principles of constructivist thinking that educators must keep in mind.

- It takes time to learn - Learning is not instantaneous. For significant learning, we need to revisit ideas, ponder them, try them out, play with them and use them

- Learning is an active process in which the learners use sensory input and constructs meaning of it. Learners need to do something because learning involves the learners engaging with the world.

- People learn to learn as they learn- Learning consist both of constructing meaning and constructing systems of meaning, that is, each meaning we construct makes us better able to give meaning to other sensations which can fit similar patterns.

- The crucial action of constructing meaning is mental - Constructing of meanings happens in the mind. We need to provide activities which engage the mind as well as the hands.

- Learning involves language- The language we use influences learning. People talk to themselves as they learn, and language and learning are inextricably intertwined.

- Learning is a social activity - Learning is intimately associated with our connection with other human beings. Conversations, interaction with others and collaborations are an integral aspect of learning. 
- Learning is contextual - We do not learn isolated facts and theories in some abstract ethereal land of mind separate from the rest of our lives. We learn in relationship to what else we know, what we believe, our prejudices and our fears.

- One needs knowledge to learn- It is not possible to assimilate new knowledge without having some structure developed from previous knowledge to build on. The more we know the more we can learn.

- Learning is not the passive acceptance of knowledge which exists "out there" Learning involves the learner engaging with the world and extracting meaning from his/her experiences.

- Motivation is a key component of learning- Motivation helps learning and is essential for learning.

\section{Pedagogical Curriculum Questions}

- Does the pedagogy value the students' points of view? The curriculum should encourage students to think reflectively for themselves. The practice should encourage student participation and problem solving and give value to students' effort to form a point of view or a considered answer to an issue of problem (Doll, 1992,Freire, 2003,Nuddings 2003)

- Does the practice encourage teaching in imaginative and creative ways? -This question highlights the duty of teachers to discuss their need for the freedom to teach their subjects artistically and guide their learners imaginatively (Hargreaves and Shirley (2008).

- Does the teacher use culturally responsive teaching? - This requires teachers to use the knowledge of their students- whether historical, religious, national, aesthetic, epistemological, political, and familial to enhance their learning and teaching. The teacher should incorporate student realities into his/her pedagogical plans (Gay 2010).

- Does student inquiry have a significant place in learning?

- Does practice draw on research related to effective methods of teaching? - ). This question is a valuable tool in seeking to determine whether, and to what degree professional development of staff is aligned with their responsibilities. The focus should be on confirming whether teachers are aware of current research related to their teaching and whether they consider their teaching habits consistent with the recommended practices (Pogrow 2009).

- Does the pedagogy reinforce written and articulated values? - This question asks teachers to determine whether their professed-written and articulated -value statement are enacted in the ways teaching is undertaken. The question of the consistency of values professed and practiced gets the heart of ethical issues (Freire, 2003).

\section{Practices that Define Constructivist Learning EnVironments}

- Providing multiple representations of reality and learning styles: over simplification of instruction by representing natural complexity of the world should be avoided. Learning of concepts must be approached via a wide range of learning contexts to promote transfer of knowledge in a broader range of domains (Kafai and Resnik, 1996). The concept of multiple representations is typical of the post-modern approaches to instruction.

- Presenting authentic tasks- Learners are more likely to view a problem from an own perspective when the situations represent context. Authentic learning occurs when instruction is designed to facilitate, stimulate and recreate real life complexities and occurrences (Cey, 2001). This is to say that the learner should be placed in situations in which they are not artificially constrained. The constructive instructional designer should therefore situate cognition in real-word contexts to facilitate the application and transfer of knowledge.

- Providing real, world, case - based learning environments, rather than pre-determined instructional sequences.

- Fostering of reflective practices to allow the learners the opportunity to develop, assess and organize their thoughts. What did students learn? Where can they transfer it? You as teacher 
should answer these questions after every teaching experience. Your students should do it also. This will help you understand if what students learned was what you planned, or something else.

- Supporting collaborative construction of knowledge through social negotiation, not competition among learners. Collaborative learning does not just entail sharing workload or coming to a consensus, it also allows learners to develop, compare and understand multiple perspectives on the issue, thus promoting insight into alternative perspectives. Learner should be able to explain and justify their thinking and openly negotiate their interpretations of the solutions to instructional tasks (Cobb and Yackel, 1995).

- Personal constructions of reality Knowledge does not come from someone else, but rather from experience. Constructivist teaching practices help learners to internalize and reshape, or transform new information (Brooks \& Brooks, 2001).

- Seeking and valuing students' points of view.

- Enhancing content- context dependent knowledge construction. This requires the application of community/service which is based on the principle of taking books to life and life to books. Meaningful learning takes place when learners develop effective ways to solve problematic situations. Inquiry learning can turn information into useful knowledge. It stresses skill development and nurtures the development of good habits of mind. Information, lacking a useful context, often has limited applications beyond passing a test. Learning plans and teaching materials need to include a relevant context for new information to lead to broader understandings. Accordingly, learning is a personal interpretation of the world.

- Focusing on inquiry-based learning. This is a useful method that educators should embrace, as it helps to enhance the learning experience of students. The method gives learners the opportunity to take a hands-on approach in their education while obtaining several important skills that can be used at all levels of their learning, and even into their future careers. It also helps to engage learners and foster excitement in the subjects they are learning about

- Adapting Curriculum to address students 'suppositions.

- Evaluation that is integrated with the task and not a separate activity

A constructionist design process should be concerned with designing environments which support the construction of knowledge which;

Is based on internal negotiation- a process of articulating mental models, using those models to explain, predict, and infer and also reflect on their utility.

Is based on social negotiation to allow sharing of reality among learner.

Is facilitated by exploration of real world environment and intervention of environment processes are regulated by each individual intentions, needs and expectations.

Requires an understanding of its own thinking process and problem solving methods- problems in one context is different from problems in other contexts.

Requires collaboration among learners and with the teacher- teacher is more of a coach or mentor than a conveyor of knowledge.

Provides an intellectual toolkit to facilitate the building of learners mental models. The Intellectual Toolkit includes critical thinking, research and information literacy teamwork/collaboration, Creativity/Innovation).

\section{STRATEgies for USING CONSTRUCTIVISM In THE Classroom}

\subsection{Use of Educational Technology}

Educational technology plays an important role in meeting the goals and objectives of project-based learning and facilitates learners' exploration and reflection on the content. Using the power of the Internet to distribute courseware is one example of how technological tools have been applied in academic settings. Combining multimedia technologies with the World Wide Web has created new possibilities for the development of instructional materials as well as for the delivery of instruction. 
Small groups' activities -Group learning activities cause learners to interpret experiences, knowledge, and beliefs and at the same time, knowledge and beliefs are found within each learner. Group activity allows them to gain new experience.

Dialogue-encourage students to engage in dialogue, both with the teacher and with one another.

\subsection{Allow Multiple Interpretations and Expressions of Learning (Multiple Intelligences)}

Encourage student inquiry- Constructionist learning theory places importance on the learners' point of view. Instructional design should make a point of including participants' requests in the design process to help bring some form of prior knowledge to presentations

\subsection{Encourage Questions and Listen when Students Speak}

\subsubsection{Metacognition and Reflection}

Metacognition is an individual's knowledge of their own cognitive processes and their ability to control these processes by organizing, monitoring and modifying them as a function of learning. It also refers to the ability to reflect on one's own performance. Reflection allows the learners the opportunity to develop, assess and organize their thoughts (Hartman, 2002).

\subsubsection{Using Models}

Models have been used continuously to help portray information in a way that can be observed by the learners. Models generally include a performance or demonstration of an activity that leads the learner to interpret the observation into useable information for processing. Other examples may include graphic pictures, electronic media, or symbolic representation of concepts.

\subsubsection{Chunking and Mnemonics}

Sometimes learners may have difficulty in retrieving information, although it may be evident that it has been "learned". Instructional strategies that have been developed in the presence of cognitive learning theory are chunking and mnemonics. Chunking is the process of grouping similar pieces of information together into a "chunk" that can be sent to working memory for rehearsal and further processing.

\subsubsection{Rehearsal}

The expression "practice makes perfect" may seem cliché, but it does fit very well when discussing cognition and development. As one rehearses, the working memory is exercised. Rehearsal is widely used in many applications where learning is necessary, particularly in educational settings. Various courses that require the rehearsal of cognitively complex tasks, like a mathematics or science course, use rehearsal as a means to assist the learners in processing the information to long-term memory.

\subsubsection{Service Learning}

Service- learning is a teaching and learning strategy that integrates meaningful community service with instruction and reflection to enrich the learning experience, teach civic responsibility, and strengthen communities' service. Service learning involves active learning-drawing lessons from the experience of performing service work. Service learning enriches student learning of course material by "bringing books to life and life to books" (Furco, 1996).

\subsubsection{Flipping the classroom}

Class time is re-purposed for inquiry, application and assessment in order to better meet the needs of the individual learners. Students gain control of the learning process through studying course material outside of class, using readings, pre-recorded video lectures or research assignments. During class time, instructors facilitate the learning process by helping students work through course material individually and in groups.

\section{ACtivities in a Constructivist Classroom}

Experimentation: Students individually perform an experiment and then come together as a class to discuss the results.

Research projects: Students research a topic and can present their findings to the class. 
Field trips: This allows students to put the concepts and ideas discussed in class in a real-world context. Field trips would often be followed by class discussions.

Films: These provide visual context and thus bring another sense into the learning experience.

Class discussions: This technique is used in all of the methods described above. It is one of the most important distinctions of constructivist teaching methods.

Peer teaching -peer teaching occurs when students, by design, teach other students. Peer teaching can enhance learning by enabling learners to take responsibility for reviewing, organizing, and consolidating existing knowledge and material; understanding its basic structure; filling in the gaps; finding additional meanings; and reformulating knowledge into new conceptual frameworks' (Dueck, 1993)."

\section{Ask open-ended questions.}

\section{Brainstorm possible alternatives}

\section{Have the learners:}

- Look for information

- Experiment with materials

- Observe phenomena

- Collect and organize data

- Employ problem-solving strategies

- Select appropriate resources, review and critique solutions.

Constructivist approaches can also be used in online learning. For example, tools such as discussion forums, wikis and blogs can enable learners to actively construct knowledge.

in the constructivist classroom both teachers and students think of knowledge not as inert fact to be memorized, but as dynamic, ever changing view of the world we live in and the ability to successfully stretch and explore that view.

\section{Comparison of a Traditional Classroom and a Constructivist Classroom}

\subsection{How does Constructivism differ from Traditional Ideas about Teaching and Learning?}

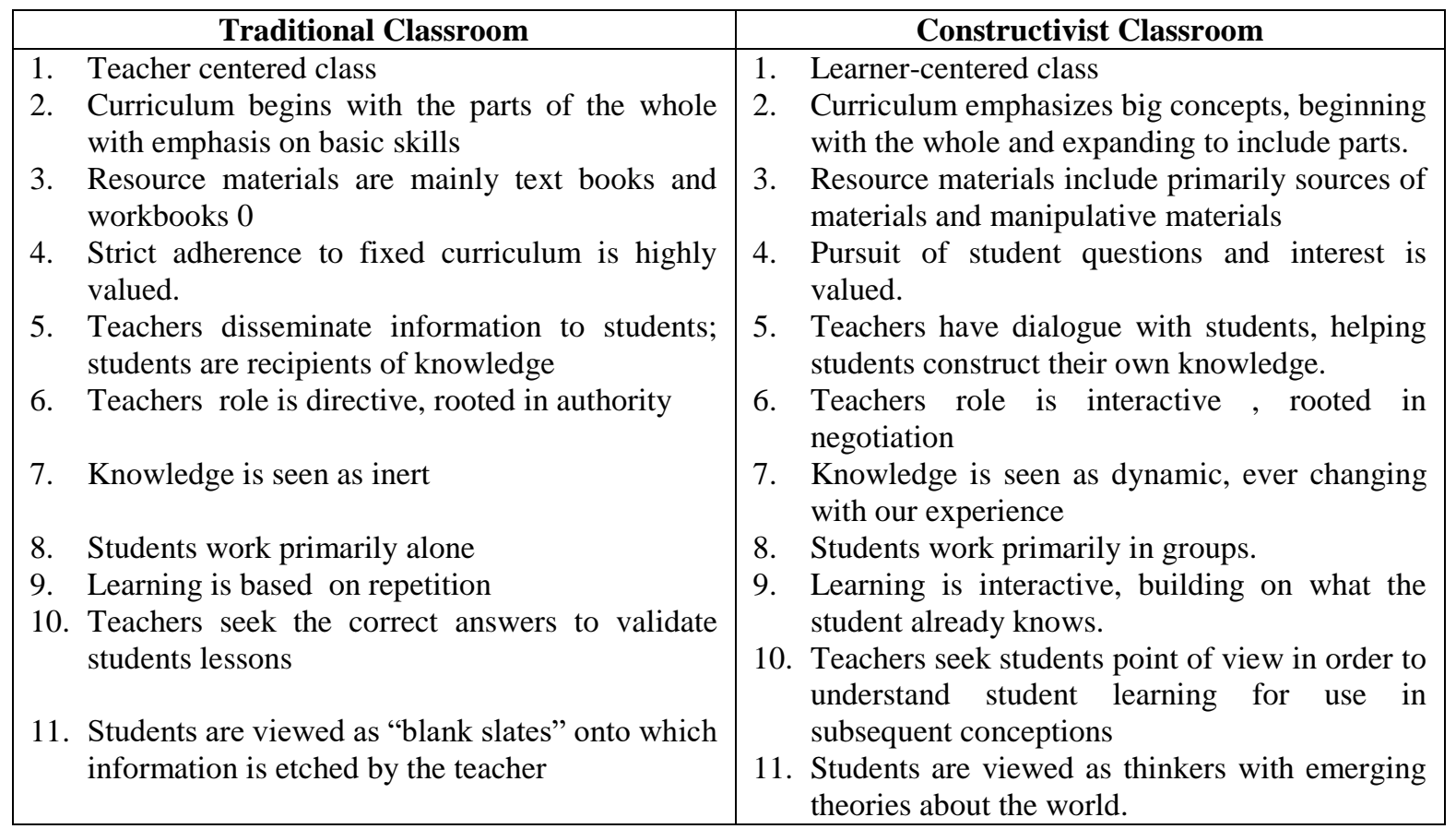

Source. Thomas \& Brown (2011) 


\section{ASSESSMENT IN A CONSTRUCTIVISM ClASSROOM}

Traditionally, assessment in the classrooms is based on testing. In this style, it is important for the student to produce the correct answers. However, in constructivist teaching, the process of gaining knowledge is viewed as being just as important as the product. Thus, assessment is based not only on tests, but also on observation of the student, the student's work, and the student's points of view. Some assessment strategies include:

- Oral discussions. The teacher presents students with a "focus" question and allows an open discussion on the topic.

- KWL (H) Chart (What we know, what we want to know, what we have learned, How we know it). This technique can be used throughout the course of study for a particular topic, but is also a good assessment technique as it shows the teacher the progress of the student throughout the course of study.

- Mind Mapping. In this activity, students list and categorize the concepts and ideas relating to a topic.

- Hands-on activities. These encourage students to manipulate their environments or a particular learning tool. Teachers can use a checklist and observation to assess student success with the particular material.

- Pre-testing. This allows a teacher to determine what knowledge students bring to a new topic and thus will be helpful in directing the course of study.

\section{CONCLUSION AND RECOMMENDATIONS}

In the constructivist classroom, students interact with the environment and create their own interpretation of the world instead of being mere recipients of information transmitted by the teacher. Through constructivism, the learner is able to construct new knowledge through multiple representation, active engagement, collaboration and inquiry with the teacher acting as facilitator. Learning is based on the active participation of learners in problem-solving and critical thinkinggiven real and authentic problems. Constructivist teaching practices help learners to internalize and reshape, or transform new information. Strategies for using constructivism in the classroom should encourage student inquiry, $\mathrm{o}$, and promote Metacognition and Reflection. The component of Service- learning as a teaching and learning strategy integrates meaningful community service with instruction and reflection to enrich the learning experience, teach civic responsibility, and strengthen communities' service. It enriches student learning of course material by "bringing books to life and life to books". The constructive instructional designer should situate cognition in real-word contexts to facilitate the application and transfer of knowledge. Appropriate intellectual toolkit such as critical Thinking, research and information literacy teamwork/collaboration, creativity/innovation is necessary to support construction of knowledge. Curriculum and instructional designs should incorporate real and authentic problems for learners to solve.

\section{REFERENCES}

[1] Brooks J. \& Brooks M. (2001). In Search of Understanding: The Case for Constructivist Classrooms. Pearson.

[2] Bruner, J. (1996). The Culture of Education, Cambridge, MA: Harvard University Press.

[3] Cey T. (2001). Moving towards constructivist. http://citeseerx.ist.psu.edu.

[4] Cobb.P \& Yackel E.(1995).Constructivist, Emergent, and Sociocultural Perspectives in the Context of

[5] Developmental Research. Washington, D.C.: National Science Foundation.

[6] Dueck, G (1993), Picture Peer Partner Learning: Students Learning From and With Each Other, Instructional Strategies Series No. 10, Saskatoon: Saskatchewan Professional Development Unit.

[7] Foerster, H. Von (2002). Observing systems. Seaside, California: Inter systems Publications.

[8] Freire, P. (2003). Pedagogy of the oppressed. New York: Continuum.

[9] Furco, A. (1996). "Service-Learning: A Balanced Approach to experiential education. "Expanding Boundaries: Service and Learning. Washington DC: Corporation for National Service.

[10] Gay, G. (2010). Classroom practices for teaching diversity: An example from Washington State (United States). In Organisation for Economic Co-operation and Development (OECD), educating teachers for diversity: Meeting the challenge (pp.257-280). Paris: OECD. 
[11] Hargreaves, A \& Shirley D. (2008) 'The fourth way: changes next exit', Educational Leadership.

[12] Hartman, H. J. (2002). Metacognition in learning and instruction. Dordreecht: Kluwer. http://www.teachnology.com/currenttrends/constructivism/piaget.

[13] Jonassen, D. H. (2000).Computers as Mind tools for schools: Engaging critical thinking.

[14] Jonassen, D. H., Peck, K. L., \& Wilson, B. G. (1999). Learning with technology: A constructivist perspective. Upper Saddle River, NJ: Prentice Hall.

[15] Kafai L. \& Resnick M( 1996). Constructionism in practice, designing, thinking, and learning in a digital World. LawrenceE rlbaum Associates.

[16] Noddings N. (2003). Is Teaching a Practice? Journal of Philosophy of Education 37(2):241 -251.

[17] Piaget J. ((1896-1980)). Theory of Constructivism.Web. 25 August. 2018.

[18] Piaget, J. (1971).The construction of reality in the child; New York: Basic Books. French original, 1937

[19] Pogrow, S. (2009). Accelerate the learning of 4thand $5^{\text {th }}$ graders born into poverty. Education Digest, 74(9), 28 33. Retrieved August 21, 2018 from Academic Search Complete. Upper Saddle River, NJ: Prentice Hall.

[20] Thomas, D., \& Brown, J. S. (2011). A new culture of learning: Cultivating the imagination for a world of constant change (Vol. 219). Lexington, KY: Create Space.

[21] Vygotsky L.S. (1962). Mind in Society: Development of Higher Psychological Processes.

\section{AUTHOR'S BIOGRAPHY}

Mercy is a curriculum specialist and lecturer at the University of Nairobi. With expertise in designing of Curriculum. Mercy has participated in Curriculum Development and review of educational programmes at National and institutional levels. In assessing achievement of learning outcomes, Mercy has participated in both formative and summative evaluation both institutionally and national level.

Citation: Mercy M. Mugambi. "Linking Constructivism Theory to Classroom Practice". International Journal of Humanities Social Sciences and Education (IJHSSE), vol 5, no. 9, 2018, pp. 96-104. doi: http://dx.doi.org/10.20431/2349-0381.0509014.

Copyright: () 2018 Authors. This is an open-access article distributed under the terms of the Creative Commons Attribution License, which permits unrestricted use, distribution, and reproduction in any medium, provided the original author and source are credited. 